\title{
Erratum to: Improved Pharmacokinetic and Biodistribution Properties of the Selective Urokinase Inhibitor PAI-2 (SerpinB2) by Site-Specific PEGylation: Implications for Drug Delivery
}

Kara Lea Vine' • Sergei Lobov' • Vineesh Indira Chandran ' • Nathanial Lachlan Ewart Harris ' • Marie Ranson'

Published online: 13 June 2015

(C) Springer Science+Business Media New York 2015

\section{Erratum to: Pharm Res}

DOI I0.1007/s I | 095-0|4-|5 |7-x

The third author in the affiliation footnote on the first page of the published article is listed as V. I. Chandran. This is incorrect. The author's given name is Vineesh and the family name is Indira Chandran. Therefore, the author's name should be listed as V. Indira Chandran.

The online version of the original article can be found at http://dx.doi.org//0. |007/s | |095-0|4-1517-x.

Marie Ranson

mranson@uow.edu.au

School of Biological Sciences, Illawarra Health and Medical Research Institute, University of Wollongong, Wollongong, NSW 2522, Australia 